\title{
SARAMPO: PERFIL EPIDEMIOLÓGICO E COBERTURA VACINAL
}

\author{
Measles: Epidemiological Profile And Vaccination Coverage
}

\author{
Bruna Mendes Santos ${ }^{1}$ \\ Ênata Luisa Oliveira Guimarães ${ }^{2}$ \\ Igor Antonio Tolentino Narciso ${ }^{3}$ \\ João Claudio Prates Medeiros ${ }^{4}$ \\ João Paulo Drumond Pires Gorayeb ${ }^{5}$ \\ Júlia Soares Oliveira ${ }^{6}$ \\ Karina Andrade de Prince ${ }^{7}$
}

Resumo: Objetivo: Analisar o perfil epidemiológico e a cobertura vacinal do sarampo no Brasil no período de 2011 a 2020. Método: Trata-se de um estudo, retrospectivo, descritivo, quantitativo, de base documental, com busca nas bases de dados do Sistema de Informações Hospitalares do Sistema Único de Saúde e do Sistema de Informações do Programa Nacional de Imunizações (SI-PNI), ambas disponibilizadas pelo Departamento de Informática do SUS (DATASUS). Resultados: No período avaliado, de 2011 a 2020, foram registrados 2.722 casos de internações por Sarampo no Brasil, com aumento de $1.445 \%$ nos anos de 2018 e 2019 e predomínio de ocorrências na região Norte $(45,0 \%)$. A partir de 2015 até 2020, houve um decréscimo da cobertura vacinal $(19,32 \%)$ e aumento na taxa de mortalidade nos anos seguintes. A doença teve predomínio no sexo masculino $(52,76 \%)$, em menores

\footnotetext{
${ }^{1}$ Graduanda de Medicina pelo Centro Universitário FIPMoc (UNIFIPMoc). Montes Claros/MG-Brasil. $\square$ mendes.bruna@outlook.com. (1) https://orcid.org/0000-0002-6789-5836.

${ }^{2}$ Graduanda de Medicina pelo Centro Universitário FIPMoc (UNIFIPMoc). Montes Claros/MG-Brasil. enata.guimaraes@aluno.unifipmoc.edu.br. 1 https://orcid.org/0000-0001-8931-0440.

${ }^{3}$ Graduando de Medicina pelo Centro Universitário FIPMoc (UNIFIPMoc). Montes Claros/MG-Brasil. $\square$ igor.narciso@gmail.com. (19 https://orcid.org/0000-0003-3656-0301.

${ }^{4}$ Graduando de Medicina pelo Centro Universitário FIPMoc (UNIFIPMoc). Montes Claros/MG-Brasil. $\square$ joaoclaudioprates@ hotmail.com. (1) https://orcid.org/0000-0002-5377-9922.

5 Graduando de Medicina pelo Centro Universitário FIPMoc (UNIFIPMoc). Montes Claros/MG-Brasil. joao.gorayeb@aluno.unifipmoc.edu.br. 19 https://orcid.org/0000-0002-4454-6326.

${ }^{6}$ Graduanda de Medicina pelo Centro Universitário FIPMoc (UNIFIPMoc). Montes Claros/MG-Brasil. $\square$ juliasoaresoliveir@gmail.com. (1) https://orcid.org/0000-0001-5958-2736.

${ }^{7}$ Doutora em Biociências e Biotecnologia Aplicadas a Farmácia (UNESP). Professora do Centro Universitário FIPMoc - (UNIFIPMoc). Montes Claros/MG - Brasil. $\square$ karina.prince@professor.unifipmoc.edu.br. (1) .. https://orcid.org/0000-0001- 8231-852X.
}

$\begin{array}{ccc}\text { Recebido em } & \text { Aceito em } & \text { Publicado em } \\ 14 / 07 / 2021 & 25 / 09 / 2021 & 09 / 11 / 2021\end{array}$


de 1 ano (37,29\%) e na cor/raça parda (50,55\%). 7,64\% das internações foram em hospitais públicos e o maior número foi por urgência $(92,32 \%)$. Quanto aos gastos relacionados às internações, $7,47 \%$ foi destinado a pacientes internados em regime público Conclusão: Nota-se a necessidade de adesão à vacinação para controle dos surtos, diminuição dos gastos e melhoria da qualidade de vida.

Palavras-Chave: Sarampo; Cobertura vacinal; Hospitalizações.

Abstract: Objective: To analyze the epidemiological profile and vaccination coverage of Measles in Brazil from 2011 to 2020. Method: This is a retrospective, descriptive, quantitative, document-based study, with the search made in the databases of the Information System of the Unified Health System (SUS) and the Information System of the National Immunization Program (SI-PNI), both made available by the SUS Department of Informatics (DATASUS). Results: In the period evaluated, from 2011 to 2020, 2,722 cases of hospitalizations for Measles were registered in Brazil, with an increase of $1,445 \%$ in the years of 2018 and 2019, and a predominance of occurrences in the North region (45.0\%). From 2015 to 2020, there was a decrease in vaccination coverage (19.32\%) and an increase in the mortality rate in the following years. The disease was predominant in males $(52.76 \%)$, in children under 1 year old (37.29\%) and in brown color/race (50.55\%). 7.64\% of admissions were in public hospitals and the largest number was for urgent hospitalizations $(92.32 \%)$. As for the expenses related to hospitalizations, $7.47 \%$ were allocated to patients hospitalized under the public system. Conclusion: There is a need for adherence to vaccination to control outbreaks, reduce expenses and improve quality of life.

Keywords: Measles; Vaccination coverage; Hospitalizations.

\section{INTRODUÇÃO}

O sarampo é uma doença aguda e infecciosa, do tipo viral, extremamente contagiosa e comum na infância ${ }^{1}$. A transmissão do vírus do sarampo, Measles morbillivirus, ocorre de forma direta, por meio de secreções nasofaríngeas expelidas ao tossir, espirrar, falar ou respirar, por dispersão de aerossóis com partículas virais no ar em ambientes fechados ${ }^{2}$. $\mathrm{O}$ quadro clínico apresenta-se com hipertermia, exantema maculopapular geralmente associado à tosse, coriza, conjuntivite e às manchas de Koplik na mucosa oral, podendo evoluir com complicações graves ${ }^{2}$.

Essa infecção provoca um estado de imunossupressão por um período de tempo, fazendo com que a pessoa fique mais vulnerável a outras infecções, diminuindo a contagem de células de defesa, como as células B e T, gerando, assim, uma linfopenia ${ }^{3,4,5}$. O vírus também é capaz de penetrar múltiplos órgãos, causando uma diversa variedade de complicações e até mesmo o óbito, porém essa gravidade pode variar, uma vez que depende da pessoa e dos fatores ambientais ${ }^{5,6}$. 
Aproximadamente $30 \%$ dos casos apresentam complicações e necessitam de internações hospitalares, sendo mais frequente em crianças menores de 5 anos, especialmente recém-nascidos e adultos entre 20 e 29 anos portadores de imunodeficiência. Dentre as possíveis complicações, tem-se: diarreia, otite, pneumonia, laringite, bronquite, encefalite aguda, hepatite, apendicite e ileocolite ${ }^{7}$.

A profilaxia dessa infecção viral é feita através da vacinação composta de vírus vivos atenuados. No Brasil, a vacina é recomendada aos 12 meses de idade, disponível na tríplice viral (sarampo, caxumba e rubéola) e aos 15 meses de idade na tetraviral (sarampo, caxumba, rubéola e varicela) $)^{8}$.

O tratamento disponível está relacionado aos sintomas e complicações da doença, não existindo tratamento antiviral específico, tendo a vacinação como o melhor modo de prevenção da doença. O Brasil chegou a receber da Organização Pan Americana de Saúde (OPAS) o certificado internacional de erradicação do sarampo em $2016^{2}, 9$, onde através da vacinação e vigilância epidemiológica conseguiu registrar nenhum caso em 12 meses, contudo, novos casos têm sido notificados no país desde 2018, o que levou à perda deste certificado ${ }^{9}$. Acredita-se que esses casos têm sido justificados pelas baixas coberturas da vacina tríplice viral ${ }^{9}$.

Mesmo com um adequado programa de imunização, o acúmulo de suscetíveis ainda pode ocorrer após alguns anos, devido à vacina não promover a soroconversão ou esta não ser duradoura ${ }^{2}$. A incompletude vacinal observada é causada por diversos fatores que necessitam ser dimensionados por novos estudos e enfrentados com as devidas estratégias, resultando em um controle mais rigoroso da enfermidade ${ }^{10}$. O ressurgimento do sarampo é um grande revés para a saúde pública, mostrando que a doença continua a representar uma ameaça real e, demanda vigilância contínua e novas formas de enfrentamento para que não volte a ser, como na década de 1970, principal causa de morte entre doenças imunopreveníveis da infância ${ }^{11}$. Com isso, o fato da doença ser uma importante causa de morbimortalidade e de hospitalizações ${ }^{10}$, o presente estudo teve como objetivo analisar o perfil epidemiológico e a cobertura vacinal do sarampo no Brasil no período de 2011 a 2020, visando promover uma melhor compreensão da evolução do perfil epidemiológico e da cobertura vacinal do sarampo no Brasil. 


\section{MÉTODOS}

Trata-se de um estudo retrospectivo, descritivo, quantitativo, de base documental com procedimento comparativo-estatístico. Teve como base de dados consultada o Sistema de Informações Hospitalares do Sistema Único de Saúde (SIH/SUS), referente ao número de internações causadas pelo sarampo e pelos dados de cobertura das vacinas tríplice e tetraviral no período de janeiro de 2011 a dezembro de 2020, pesquisados no Sistema de Informações do Programa Nacional de Imunizações (SI-PNI). Os dados foram obtidos a partir do SIH/SUS, disponibilizados pelo Departamento de informática do Sistema Único de Saúde (DATASUS), no endereço eletrônico (http://www2.datasus.gov.br) e pelo SI-PNI, no endereço eletrônico (http://sipni.datasus.gov.br/).

A coleta de dados ocorreu no mês de março de 2021 por meio da utilização do programa de Informações em saúde (TABNET). A tabulação dos registros do SIH/SUS e SIPNI para esta pesquisa incluiu: variáveis sociodemográficas (sexo, faixa etária e etnia); clínicas (número de internações e média de permanência, taxa de mortalidade, caráter, regime de atendimento e custos das internações); e a cobertura vacinal por ano e região.

Para o cálculo da prevalência e cobertura vacinal foram utilizados os dados referentes à população estimada por região e estado, através do Instituto Brasileiro de Geografia e Estatística (IBGE), no endereço eletrônico (http://www.ibge.gov.br). Foi realizada análise descritiva das variáveis, com frequência, porcentagem e a média do número de casos registrados. A análise bivariada foi realizada por meio do teste Qui-quadrado de Pearson.

Foi considerado como nível de significância, o valor de $\mathrm{p}<0,05$. Utilizou-se o software Microsoft Office Excel® e o programa Statistical Package for the Social Sciences ${ }^{\circledR}$ (SPSS) para Windows®, versão 25 (Chicago, IL, USA), para gerenciamento e análise de dados.

Tendo em vista que a pesquisa se baseou em dados disponibilizados em meio eletrônico pelo Ministério da Saúde, sendo esses de domínio público e, pelo fato de haver sigilo acerca das informações de identificação inerentes aos seres humanos envolvidos, este estudo dispensa a apreciação e a aprovação pelo Comitê de Ética em Pesquisa. 


\section{RESULTADOS}

No período de 2011 a 2020 foram registrados um total de 2.722 casos de internações por Sarampo no Brasil. O número de internações por ano por sarampo variou de 896 a 38, com média de 272 casos. Observou-se um aumento expressivo no número de internações entre 2017 e 2019 (1.445\%) e, um decréscimo em 2020 (43,86\%) (Figura 1).

Analisando o número de internações por ano de acordo com as regiões do Brasil, observou-se que até o ano de 2017, embora com oscilações, havia controle do número de internações em todas as regiões do país. Em 2018, na Região Norte ocorreu o maior número de internações (825 casos). Já nas regiões Nordeste, Sudeste e Centro-Oeste o maior número de internações ocorreu em 2019 (107, 684 e 20 casos, respectivamente) e na região Sul em 2011 (41 casos).

Figura 1 - Número de internações e taxa de mortalidade por sarampo no Brasil, 2011 a 2020.

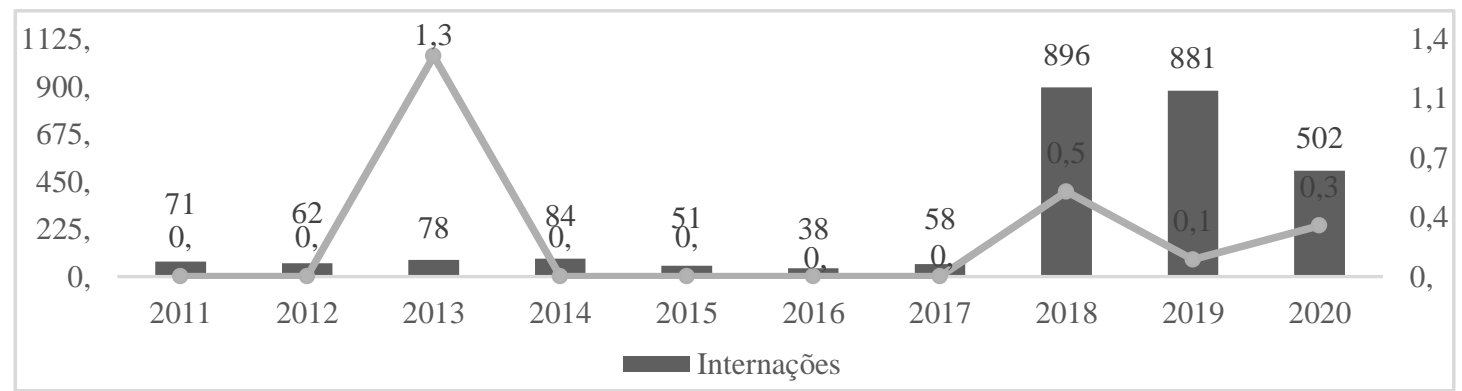

Fonte: Ministério da Saúde - Sistema de informações hospitalares do SUS (SIH/SUS), 2021.

Em relação ao número de internações e taxa de mortalidade por região, verifica-se um maior número de internações na região Norte $(45,0 \%)$ e Sudeste $(32,1 \%)$. No entanto, a maior taxa de mortalidade concentram-se na região Sul $(0,6)$ (Figura 2).

Figura 2 - Número de internações e taxa de mortalidade por sarampo de acordo com as regiões do Brasil, 2011 a 2020.

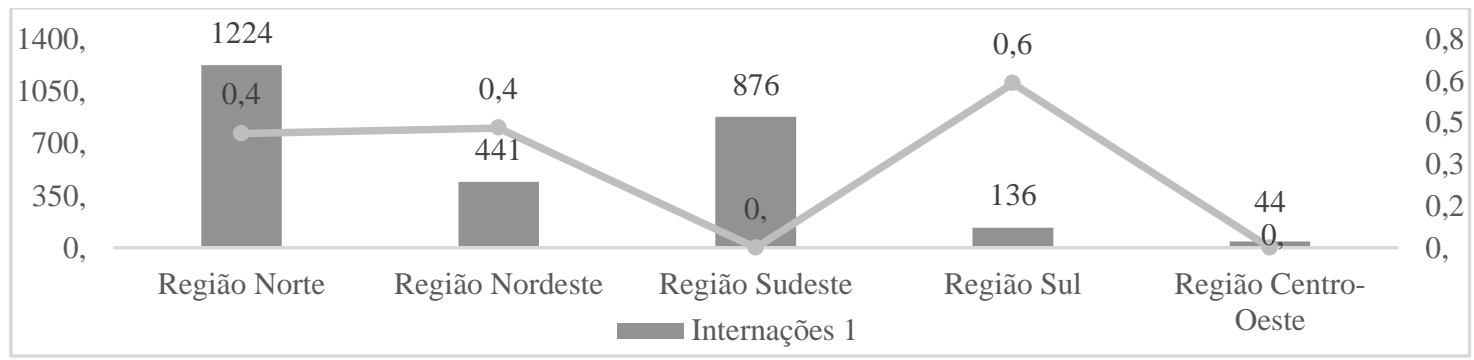

Fonte: Ministério da Saúde - Sistema de informações hospitalares do SUS (SIH/SUS), 2021. 
Analisando as coberturas vacinais e as taxas de mortalidade, nota-se maiores números de cobertura vacinal em 2014 (102,84\%), 2011 (102,39\%), 2012 (99,5\%). Nestes anos a taxa de mortalidade foi zero, a qual se repetiu nos anos 2015, 2016 e 2017. Observa-se que em 2013 houve queda na cobertura vacinal $(88,17 \%)$ e a maior taxa de mortalidade (1,28\%). Verifica-se também um decréscimo da cobertura vacinal a partir de 2015 até 2017, com um um aumento progressivo de 2018 a 2019, e retorno à queda em 2020. Nos anos de 2013, 2018, 2019 e 2020 a taxa de mortalidade foi de 1,3, 0,5, 0,1 e 0,2 respectivamente.(Figura 3).

Figura 3 - Cobertura vacinal e taxa de mortalidade por sarampo no Brasil, 2011 a 2020.

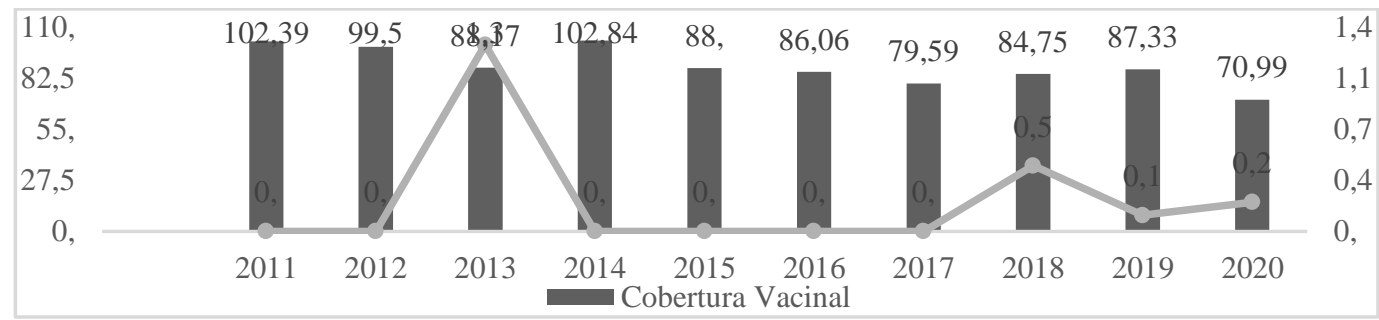

Fonte: Ministério da Saúde - Sistema de informações hospitalares do SUS (SIH/SUS), 2021.

Quanto à cobertura vacinal de acordo com as regiões brasileiras, identifica-se o maior percentual na região Sul $(90,25 \%)$ e o menor na região Norte $(78,95 \%)$. Comparada a esses dados, a média de internações por ano/100.000 habitantes foi maior na região Norte $(0,66)$ e menor na região Centro-Oeste $(0,03)$ e Sul $(0,05)$ (Figura 4$)$.

Figura 4 - Mapa da cobertura vacinal e da prevalência de internações por sarampo no Brasil, 2011 a 2020.

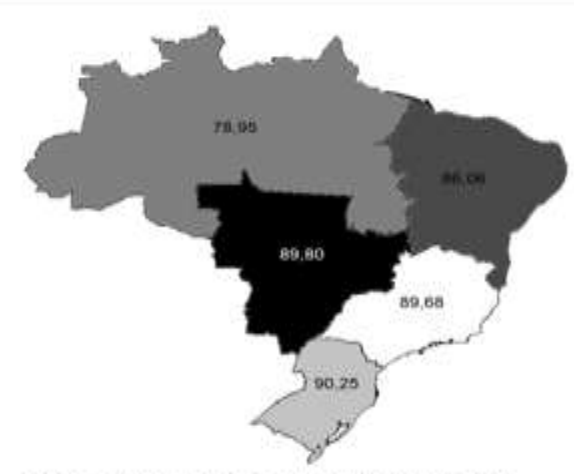

Mapa epidemiológico da cobertura vacinal

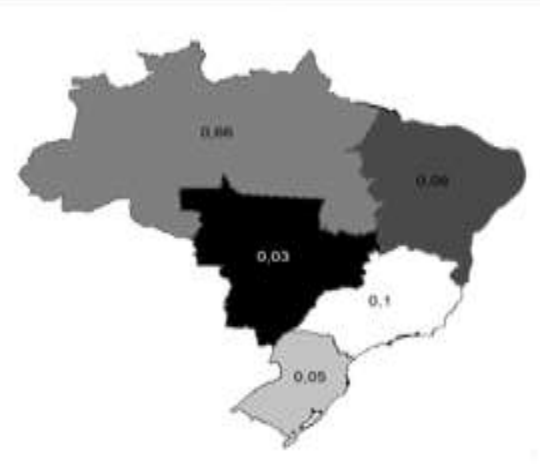

Prevalência internaçòes por $100 \mathrm{mil}$ habitantes

Fonte: Ministério da Saúde - Sistema de informações hospitalares do SUS (SIH/SUS), 2021. 
De acordo com os dados sociodemográficos e clínicos dos pacientes internados, houve diferenças estatisticamente significativas entre as variáveis avaliadas $((\mathrm{p}<0,004$ e $\mathrm{p}<$ 0,001). Nota-se o predomínio de casos no sexo masculino $(52,76 \%)$, na faixa etária de menores que 1 ano $(37,29 \%)$ e na cor/raça parda (50,55\%). Em relação ao regime, o maior percentual se encontrava ignorado $(87,40 \%)$. Quanto ao caráter de internação, o maior número foi por urgência (92,32\%). No que diz respeito à média de permanência, o setor privado obteve a maior média (6,1 dias). Analisando os gastos relacionados às internações, o valor total foi de $898.721,25$ reais e o maior percentual destes se encontravam ignorados $(88,75 \%)$ (Tabela 1).

Tabela 1 - Dados sociodemográficos e clínicos dos pacientes internados por sarampo no Brasil, 2011 a 2020.

\begin{tabular}{|c|c|c|c|}
\hline Variáveis & Total & $\%$ & Valor de $p$ \\
\hline Total & 2.722 & 100 & \\
\hline Sexo & & & 0,004 \\
\hline Masculino & 1436 & 52,76 & \\
\hline Feminino & 1286 & 47,24 & \\
\hline Faixa etária & & & $<0,001$ \\
\hline Menor que 1 ano & 1015 & 37,29 & \\
\hline 1 a 4 anos & 712 & 26,16 & \\
\hline 5 a 9 anos & 202 & 7,42 & \\
\hline 10 a 14 anos & 118 & 4,34 & \\
\hline 15 a 19 anos & 151 & 5,55 & \\
\hline 20 a 29 anos & 282 & 10,36 & \\
\hline 30 a 39 anos & 113 & 4,15 & \\
\hline 40 a 49 anos & 55 & 2,02 & \\
\hline 50 anos e mais & 74 & 2,72 & \\
\hline Cor/raça & & & $<0,001$ \\
\hline Branca & 496 & 18,22 & \\
\hline Preta & 38 & 1,40 & \\
\hline Parda & 1376 & 50,55 & \\
\hline Amarela & 27 & 0,99 & \\
\hline Indígena & 9 & 0,33 & \\
\hline Sem informação & 776 & 28,51 & \\
\hline Regime & & & $<0,001$ \\
\hline Público & 208 & 7,64 & \\
\hline Privado & 135 & 4,96 & \\
\hline Ignorado & 2379 & 87,40 & \\
\hline Caráter & & & $<0,001$ \\
\hline Eletivo & 209 & 7,68 & \\
\hline Urgência & 2513 & 92,32 & \\
\hline
\end{tabular}




\begin{tabular}{lccc}
\hline Média de permanência & & & Não se aplica \\
Público & 4,4 & & \\
Privado & 6,1 & & \\
Ignorado & 4,3 & & \\
Total & 4,2 & 7,47 & \\
\hline Valor Total & & 3,78 & \\
Público & $67.168,12$ & 88,75 & \\
Privado & $33.963,58$ & 100,00 & \\
Ignorado & $797.589,55$ & $898.721,25$ & \\
Total & & & \\
\hline
\end{tabular}

Fonte: Ministério da Saúde - Sistema de Informações Hospitalares do SUS (SIH/SUS), 2021.

\section{DISCUSSÃO}

No ano de 1968 o sarampo tornou-se uma doença de notificação compulsória, principalmente por ter sido uma das maiores causas de óbito em crianças menores de cinco anos de idade nesse período11. Nessa mesma década, a vacinação foi implementada, e sua adesão inicial no sistema de saúde mostrou-se essencial no combate à doença12, contribuindo para a redução da morbimortalidade pela doença.

No entanto, no período de 2011 a 2020 foram registrados um total de 2.722 casos de internações por sarampo no Brasil. Sendo que, nos anos de 2018 e 2019 houve um aumento significativo dessas internações $(1.445 \%)$, assim como um decréscimo da cobertura vacinal a partir de 2015 e um aumento na taxa de mortalidade. Nesse sentido, há a possibilidade de relacionar a diminuição da cobertura vacinal com o aumento da incidência do sarampo no país em 2018 e 2019 e, consequentemente, aumento do número de internações e óbitos pela doença.

Neste periodo, na região Norte houveram intensos movimentos migratórios de países fronteiriços ao Brasil, que contribuiram para a propagação do vírus do sarampo na região, não havendo na mesma proporção a manutenção da coberturas vacinais adequadas12, 13. Posteriormente, o vírus foi introduzido e espalhado para áreas mais densamente povoadas, como o sudeste, gerando um maior impacto. Embora a cobertura da vacinação contra o sarampo na região sudeste seja de quase $90 \%$, ainda não é o suficiente para combater o surto14.

A cobertura vacinal de mais de $95 \%$ é a maneira mais eficaz de manter a população livre do sarampo e pode impedir a propagação do vírus em qualquer circunstância16. A baixa cobertura vacinal é um dos principais fatores que influenciam 
diretamente no aumento dos casos de doenças imunopreveníveis, que decorrem da crescente desinformação da população referente às vacinas e seus benefícios15.

Assim, os surtos da doença que ocorreram em 2018 e 2019, a partir da entrada do vírus junto com turistas doentes e imigrantes suscetíveis, somados à diminuição da cobertura vacinal11, 14, 15, impactaram diretamente no aumento percentual de internações e na taxa de mortalidade pela doença ocorridos no Brasil.

Teorias sobre a razão do novo surto podem estar relacionadas também a um possível decaimento dos níveis de anticorpos após a imunização, resposta imunológica não eficiente contra o genótipo D8 ou associação a alguns fatores genéticos. Contudo, questões sociais e políticas também são significativas para explicar o ocorrido, como as dificuldades apresentadas no sistema de saúde, os grupos antivacinas espalhados pelo mundo e o aumento da possibilidade de viagens entre países no atual mundo globalizado16, 17.

Analisando o número e a prevalência de internações de acordo com as regiões do Brasil, observou-se que até o ano de 2018, embora com oscilações, havia controle do número de internações em todas as regiões do país. Em 2018, nas Regiões Norte (825/45\%) e Sudeste $(684 / 32 \%)$ ocorreram os maiores números de internações e consequentemente maiores taxas de prevalência nessas regiões no período avaliado (0,66 e 0,1 casos por 100 mil habitantes respectivamente). Quanto à cobertura vacinal, a região Norte apresentou o menor percentual $(78,95 \%)$. Esses dados se assemelham aos encontrados em outro estudo realizado no país17.

Analisando os dados da Região Sul entre 2011 e 2020, ela encontra-se com a maior taxa de mortalidade $(0,59)$. Em contrapartida, obteve o maior percentual de cobertura vacinal $(90,25 \%)$ e a segunda menor média de internações $(0,05)$ entre as regiões brasileiras. Não foram encontrados estudos que justifiquem o maior percentual de cobertura vacinal e taxa de mortalidade nessa região. É possível que esses dados estejam refletindo uma maior eficiência dos sistemas de notificação na região Sul, o qual oferece um melhor serviço de vacinação e estrutura, além de uma melhor qualidade da atenção básica quando comparada com as regiões Norte e Nordeste18,19.

Diante dos dados sociodemográficos, os resultados mostraram um leve predomínio no sexo masculino (52,76\%), o que mostra o acometimento indistinto da doença em ambos os sexos. Além disso, acomete mais indivíduos da cor/raça parda $(50,55 \%)$, 
provavelmente por essa população ser prevalecente no Brasil, o que corrobora o fato do sarampo ser uma doença universal, não se diferenciando entre gênero e raça20.

Notou-se maior número de internações por sarampo nas faixas etárias de menores de 1 ano (37,29\%), de 1 a $4(26,16 \%)$ e 20 a 29 anos (10,36\%). Outros estudos também demonstram a alta de internações hospitalares nessas faixas etárias21, 17.

$\mathrm{O}$ alto número de internações em menores de 1 ano justifica-se em razão de não possuírem anticorpos contra a doença, uma vez que a primeira dose de rotina contra o sarampo é dada a partir dos 12 meses de vida. Para atenuar esse risco, o Ministério da Saúde instituiu, em agosto de 2019, a dose zero para crianças de seis meses a 11 meses e 29 dias. No entanto, é importante esclarecer que apenas essa dose não garante a proteção necessária contra o sarampo13. A baixa cobertura vacinal em crianças de 1 a 5 anos, sendo menores que a meta estabelecida pelo Ministério da Saúde, tem contribuído para o atual perfil de surto de alguns estados.

A imunização não é limitada ao público infantil, porém, é o principal foco para garantir uma barreira de proteção com intuito de conter o vírus15. A prevenção contra a doença baseia-se na imunização tanto individual, da faixa etária de 1 a 5 anos, quanto coletiva, onde confere resistência a um determinado grupo à disseminação do vírus, o que beneficia indivíduos vulneráveis, como menores de um ano e na faixa dos 20 a 29 anos22.

Quanto ao caráter de internação, o maior número foi por urgência $(92,32 \%)$, fato também destacado em outro estudo17. No que diz respeito à média de permanência das internações, o setor privado obteve a maior média (6,1 dias). Analisando os gastos relacionados às internações entre os anos de 2011 e 2020 no Brasil, o valor total foi de 898.721,25 reais e o maior percentual desses se encontravam ignorados. Os dados epidemiológicos sobre a média de permanência e gastos com internações são escassos na literatura, não permitindo fazer uma comparação mais fidedigna.

A percepção do risco de contaminação e óbito diminui quando a população não presencia com frequência as mortes e incapacidades decorrentes da doença12, 23. Surgem também os medos dos efeitos adversos e a propagação de falsas notícias, que se sobrepõem aos conhecimentos científicos dos benefícios da vacina12, 24.

No entanto, a prevenção por meio da vacinação é ainda uma das principais e mais eficazes medidas de prevenção e erradicação do sarampo. Além de evitar óbitos, diminui, de 
forma significativa, os gastos públicos com internações, promove o aumento da expectativa de vida e proporciona proteção, prevenção e promoção à saúde15, 22.

O estudo possui limitações devido ser proveniente de banco de dados online (DATASUS e SI-PNI), os quais possuem uma enorme quantidade de dados, compostos por milhares de variáveis que precisam ser associadas entre si, e que não há uma integração entre as bases de dados, podendo levar a erros de análises e de informações25. Somado a isso, ocorrem variações na cobertura de coleta de dados entre as regiões do país, logo os dados podem estar subnotificados 21.

\section{CONCLUSÃO}

Os dados epidemiológicos apresentados mostram uma recorrência do sarampo com maior predomínio na região Norte do país e uma diminuição da cobertura vacinal entre os anos de 2015 e 2020 em todo o Brasil, com aumento do níumero de internações e da taxa de mortalidade da doença a partir de 2018, mostrando que a doença continua sendo uma ameaça a população e ao sistema de saúde do país.

Por conseguinte, o retorno do sarampo reforça a necessidade de um plano de ação para garantir a eliminação e impedir a instauração de novas epidemias. O fortalecimento da vigilância epidemiológica para detecção de novos casos, tanto de suspeitos como de casos confirmados, ampliação da cobertura vacinal com pelo menos $95 \%$ da população vacinada com a primeira e segunda doses, políticas públicas de combate a desinformação sobre as vacinas e seus efeitos colaterais, permitindo um aumento da adesão da população à vacinação e, por consequência, diminuição dos gastos com internações de uma doença imunoprevinível, assim melhorando a qualidade de vida da população, para, quem sabe, em um futuro próximo, o Brasil retome o seu certificado de país que erradicou o sarampo, da forma como fez em 2016.

\section{REFERÊNCIAS}

1. REYES, Nathalia Kathleen Santana et al. Modelagem Matemática para a Vacinação contra o Sarampo. Proceeding Series of the Brazilian Society of Computational and Applied Mathematics, São Carlos, v. 7, n. 1, 2020. 
2. DE MORAES, Marluce Matos et al. Estudo soroepidemiológico do sarampo em populações residentes na Região Metropolitana de Belém, estado do Pará, Brasil, 2016 a 2018. Revista Pan-Amazônica de Saúde, Ananindeua, v. 11, p. 1-11, set, 2020.

3. BHATTACHARJEE, Sankhajit.; YADAVA, Pramod Kumar. Measles virus: background and oncolytic virotherapy. Biochemistry and Biophysics Reports, New Delhi, v. 13, p. 58-62, mar, 2018.

4. ROTA, Paul A et al. Measles. Nature Reviews Disease Primers, New York, v. 2, n. 16049, p. 1-16, jul, 2016.

5. GOODSON, James L.; SEWARD, Jane F. Measles 50 years after use of measles vaccine. Infectious Disease Clinics, Philadelphia, v. 29, n. 4, p. 725-743, dez, 2015.

6. WHO. World Health Organization. Measles vaccines: WHO position paper - April 2017. Weekly Epidemiological Record, Geneva, v. 92, n. 17, p. 205-228, abr, 2017.

7. DE VASCONCELOS, Lidiane Assunção et al. Análise epidemiológica do sarampo entre os estados brasileiros que fazem fronteira com outros países, Brasil, 2015 a 2018. Research, Society and Development, Vargem Grande Paulista, v. 9, n. 6, p. 115 , abr, 2020.

8. TAVARES, Walter; MARINHO, Luiz Alberto Carneiro. Rotinas de diagnóstico e tratamento das doenças infecciosas e parasitárias. São Paulo: Atheneu, 2015.

9. FIGUEREDO, Alessandra Almeida Silva.; VIEIRA, Maria Amélia.; BEZERRA, Kátia Floripes. Panorama do Surto de Sarampo nas Regiões Brasileiras: Um Reflexo da Baixa Cobertura da Tríplice Viral na Última Década. Conhecimento \& Ciência. Belém, v. 1, p. 106, 2020.

10. RODRIGUES, Bruna Larissa Pinto et al. Atualizações sobre a imunização contra o sarampo no Brasil: uma revisão sistemática. Revista Eletrônica Acervo Saúde, São Paulo, n. 55, e3919, ago, 2020.

11. FARIA, Shirley Cristiane Ramalho Bueno de; MOURA, Ana Débora Assis. Atuação de equipes da Estratégia Saúde da Família frente à epidemia de sarampo em Fortaleza, Ceará, Brasil. Epidemiologia e Serviços de Saúde, Brasília, v. 29, n. 3, e2018208, maio, 2020. 
12. DOMINGUES, Carla Magda Allan Santos et al. Vacina Brasil e estratégias de formação e desenvolvimento em imunizações. Epidemiologia e Serviços de Saúde. Brasília, v. 28, n. 2, e20190223, out, 2019.

13. ELÍDIO, Guilherme Almeida et al. Sarampo. Boletim Epidemiológico [Internet], Brasília, v.50, n. esp, p.66-67, set, 2019. (Número especial: Vigilância em Saúde no Brasil 2003|2009: da criação da Secretaria de Vigilância em Saúde aos dias atuais). Disponível em: http://www.saude.gov.br/ boletins-epidemiologicos. Acesso em: 8 maio, 2021.

14. MEDEIROS, Eduardo Alexandrino Servolo. Entendendo o ressurgimento e o controle do sarampo no Brasil. Acta Paulista de Enfermagem, São Paulo, v. 33, eEDT20200001, mar, 2020.

15. CHAVES, Elem Cristina Rodrigues et al. Avaliação da cobertura vacinal do sarampo no período de 2013-2019 e sua relação com a reemergência no Brasil. Revista Eletrônica Acervo Saúde, São Paulo, n. 38, e1982, jan, 2020.

16. ESCALANTE, Giovanni. El retorno del sarampión en las Américas. Revista Médica del Uruguay, Montevideo, v. 35, n. 2, p. 1-3, jun, 2019.

17. WANDERLEY, Renata Lins et al. Perfil epidemiológico das ocorrências de sarampo no Brasil durante os últimos 5 anos. Brazilian Journal of Development, Curitiba, v. 7, n. 1, p. 3784-3794, jan, 2021.

18. ALBUQUERQUE, Laine Côrtes. Avaliação dos serviços de vacinação nas unidades básicas de saúde do Brasil. Dissertação (Mestrado) - Programa de Pós-graduação em Saúde Coletiva/CCBS, Universidade Federal do Maranhão, São Luís, 2017.

19. DE ABREU, Daisy Maria Xavier et al. Análise espacial da qualidade da Atenção Básica em Saúde no Brasil. Saúde em Debate, Rio de Janeiro, v. 42, n. esp 1, p. 67-80, jul, 2018.

20. ALMEIDA, Carla Cecília da Costa et al. Estudo epidemiológico de pacientes infectados por sarampo no Brasil. Brazilian Journal of Health Review, Curitiba, v. 3, n. 2, p. 1513-1526, mar/abr, 2020.

21. SOUZA, Amanda Carvalho Ferreira de et al. Aspectos epidemiológicos das internações por sarampo no brasil entre 2018 e 2019. Revista Saber Digital, Valença, v. 13, n. 2, p. 88-98, dez, 2020. 
22. GARCIA, Liliane Rodrigues et al. A importância da vacinação no combate ao sarampo. Brasilian Journal of Health Review, Curitiba, v. 3, n. 6, p. 16849-16857, nov/dez, 2020.

23. VICTORA, Cesar G. 40 anos do Programa Nacional de Imunizações: o desafio da equidade. Epidemiologia e Serviços de Saúde, Brasília, v. 22, n. 2, p. 201-201, jun, 2013.

24. APS, Luana Raposo de Melo Moraes et al. Adverse events of vaccines and the consequences of non-vaccination: a critical review. Revista de Saúde Pública, São Paulo, v. 52, p. 40, abr, 2018.

25. KUIAVA, Eliseu Luiz et al. Sistema computacional automático para geração de relatórios epidemiológicos a partir de dados do datasus. Brazilian Journal of Health Review, Curitiba, v. 3, n. 6, p. 17549-17558, nov/dez, 2020. 